\title{
Use of Cement Gun for Fixation of Tibia Component in Total Knee Arthroplasty
}

\author{
R Yoga, MS Ortho, N Sivapathasundaram*, MS Ortho, C Suresh**, MS Ortho \\ Department of Orthopaeadics, Sultanah Aminah Hospital, Johor Bahru, Malaysia \\ *Department of Orthopaedics, Malacca Hospital, Malacca, Malaysia \\ ${ }^{* *}$ Department of Orthopaedics, Alor Star Hospital, Alor Star, Malaysia
}

\begin{abstract}
We evaluated the efficacy of a cement gun to improve the depth of cement penetration in total knee arthroplasty. Ninety-one consecutive patients from two hospitals were recruited for this study. For Group I cement was applied to the tibial baseplate and the proximal tibia with fingers. Group 2 had similar application of cement to the tibial baseplate but cement was pressurized into the proximal tibia using a cement gun.. The knee was kept extended until the cement hardened. Standard post-operative x-rays were reviewed to assess cement penetration into the proximal tibia. The mean cement penetration was $2.1 \mathrm{~mm}$ in Group 1 and $3.1 \mathrm{~mm}$ in Group 2 and the difference was statistically significant. The use of the cement gun improves cement penetration into the proximal tibia and facilitates early stability of the implant fixation to the bone.
\end{abstract}

Key Words:

Total Knee Arthroplasty, Cementation, Cement Gun, Cement penetration, Fixation, Loosening, Failure

\section{INTRODUCTION}

Despite improvements in the design of total knee arthroplasty (TKA), component loosening is still one of the most common modes of failure ${ }^{1-3}$. Most component loosening of the tibia is technique related ${ }^{4}$; micromotion between the component and the bone is believed to initiate loosening ${ }^{5,6}$. Components may also sink or subside into bone because of loss of local bone density following TKA ${ }^{7-9}$. Most surgeons use fully cemented TKA ${ }^{10}$.

Fixation to the cancellous surface is achieved in two ways. Firstly, the congruent cement mantle to the cut bone surface and secondly, interdigitation between the cement and bony trabeculae. The tensile and shear strength of bone cement interface are significantly influenced by several factors, including methods of preparation, cleaning the cut surface of the tibia, depth of cement penetration, quality of bone interdigitation with the cement and timing of cement insertion, and the size of the blade used to make the bone cuts ${ }^{11,12}$. The lack of cement and bony trabeculae interdigitation appears as a well defined cement bone interface on plain radiograph. Studies have shown that the rate of aseptic loosening can be as high as 10 percent ${ }^{13}$. Good cementing technique will improve the initial mechanical interlock between the implant and bone.

While third generation cementing technique in total hip arthroplasty is a well recognized practice, there is no specific recommendation for cementing technique in TKA. One commonly used technique is to apply cement to the implant and cut bone surfaces with fingers. The implant is then applied and impacted using a mallet ${ }^{14}$. Another technique rely on negative pressure in the form of tibia canal suction ${ }^{15}$ to improved penetration of the cement into the bone ${ }^{16}$.

Use of a cement gun is a well established practice in hip arthroplasty ${ }^{17-22}$, and it generally allows for good cement penetration. The aim in this study was to find out if it was possible to improve cement penetration during TKA with the use of cement gun. Our hypothesis was that cementing using a cement gun would increase the cement penetration into the proximal tibia.

\section{MATERIALS AND METHODS}

One hundred consecutive patients from two different hospitals were included for inclusion into this retrospective study. Surgeries were performed by three different surgeons. The first author was either the primary surgeon or assistant in all cases. The patients were divided into 2 groups. Group 1 comprised of patients who were treated in Sultanah Aminah Hospital in Johor Bahru, while group 2 comprised of patients who were treated in Alor Star Hospital.

Operative technique for group 1:

After tourniquet application, a midline incision was made and a medial parapatellar approach used to access the knee joint. After the appropriate bone cuts were made, the bone was washed with a lavage gun. After drying, hydrogen peroxide solution was applied to keep the cut bone surfaces free of blood. All patients in this group had cement applied 
to the base of tibial implant and cut tibial surface with fingers. No attempt was made to force the cement into the tibia surface, and no cement was inserted into the tibial medullary canal. Subsequent impaction with the tibial base plate was carried out with a mallet. The femoral implant was then inserted. After removing excess cement, a trial tibial insert was placed and the knee was kept extended until the cement hardened.

Operative technique for group 2:

After tourniquet application, an identical surgical approach was used till cementing step. Approximately 4 minutes after mixing (activation) cement was applied to the cut surfaces of the tibia using a cement gun (Figure 1). During this procedure, the cement gun was directed perpendicular to the cut dry bone surfaces. This pressurized the cement into the cut surface of the tibia. As the nozzle of the cement gun was small compared to the cut surface of the tibia, multiple pressurizations were attempted at different locations in the tibia until the whole surface was fully covered with injected cement. Fat and marrow could be seen being extruded during this procedure indicating good pressurization. Some cement was applied to the undersurface of the tibia and femur implant. Impaction was accomplished in a similar manner as for patients in Group 1. The femoral implant was subsequently applied. After removal of excess cement, a trial tibial insert was then placed and the knee was kept extended until the cement hardened.

Standard anterior-posterior and lateral postoperative x-rays were taken post-operatively. A senior radiologist (5 years post specialization) who was blinded to the surgical technique then reviewed the radiographs. The depth of cement penetration was measured using a digital caliper (accurate to $0.1 \mathrm{~mm}$ ) and localized using the Knee Society Zones Roentgenographic Evaluation ${ }^{23}$. In this study, only zones 1 to 4 (Figure 3) of the antero-posterior radiographs (Figure 3 ) and zones 1 to 2 on the lateral tibial radiographs (Figure 3) were measured. Zones 1 to 2 on the lateral tibial radiographs were then renamed zones 8 and zones 9 for purpose of evaluation in this study. Cement penetration at zones $3,5,6$, and 7 was not studied.

The depth of cement penetration was compared for the same zones in the two different groups. They were then compared between zones of the same group to find if cementing was better or worse in certain locations in the tibia. The appearance or absence of a radiolucent line between the cement and the bone was also recorded, as it can be assumed that the radiolucent line may indicate poor bone penetration ${ }^{24}$.

Statistical analysis was performed using the Statistical Package for Social Sciences (SPSS) software package. The data was not found to be normally distributed. Non parametric analysis of variance using the Kruskal-Wallis test was then performed.

\section{RESULTS}

Of the 100 patients selected for the study, nine were excluded. These include a patient with a large bone cyst, another patients with severe osteoporosis, three patients with marked deformity secondary to rheumatoid arthritis, and four patients with no proper anteroposterior and lateral radiographs. Group 1 comprised of 47 patients with a mean age 62 years ( 40 females and 7 males). Group 2 comprised of 44 patients with a mean age of 63.5 years ( 34 females and 10 males).

The mean cement penetration was $2.1 \mathrm{~mm}$ (median $2.0 \mathrm{~mm}$ ) in Group 1 and was $3.1 \mathrm{~mm}$ (median $3.0 \mathrm{~mm}$ ) in Group 2, a statistically significant difference $(\mathrm{p}<0.001)$. When we compare various zones between the 2 groups, cement penetration was significantly better in all zones except for zones 1 and zones 2 in group 2 suggesting a beneficial outcome with the use of a cement gun $(\mathrm{P}<0.001)$ (Figure 4). The incidence of a radiolucent line occurring in any zone was $87.2 \%$ in Group 1 and $34.1 \%$ in Group 2, also a statically significant difference $(\mathrm{P}<0.001)$. We did not analyse which zone had the appearance of a radiolucent line as loosening in any zone is important.

\section{DISCUSSION}

Loosening of total knee prostheses starts with the tibial component, therefore, research addressing micromotion of tibial components fixed using different techniques is of interest. After prosthetic implantation, bone resorption due to micromotion occurs but it will settle down after a period of time ${ }^{9}$. However, in some patients this initial resoption continues even after one or two years and eventually resulting in progressive loosening of the implant ${ }^{25}$.

Table I: Male to female proportions of the two study groups

\begin{tabular}{|lcc|}
\hline & $\begin{array}{c}\text { Group 1 } \\
(\mathbf{n = 4 7 )}\end{array}$ & $\begin{array}{c}\text { Group 2 } \\
(\mathbf{n = 4 4 )}\end{array}$ \\
\hline Mean age (years) & 62 & 63.5 \\
Males & 7 & 10 \\
Females & 40 & 34 \\
\hline
\end{tabular}

Table II: Median Cement penetration ( $\mathrm{mm}$ ) in the tibia in both groups of patients

\begin{tabular}{|ccc|}
\hline & $\begin{array}{c}\text { Median cement penetration } \\
\text { Group 1 }\end{array}$ & Group 2 \\
\hline Zone 1 & 1.7 & 2.1 \\
Zone 2 & 2 & 2.3 \\
Zone 3 & 2.1 & 3.5 \\
Zone 4 & 1.7 & 3.2 \\
Zone 7 & 1.8 & 3.3 \\
Zone 8 & 1.8 & 3.1 \\
\hline
\end{tabular}




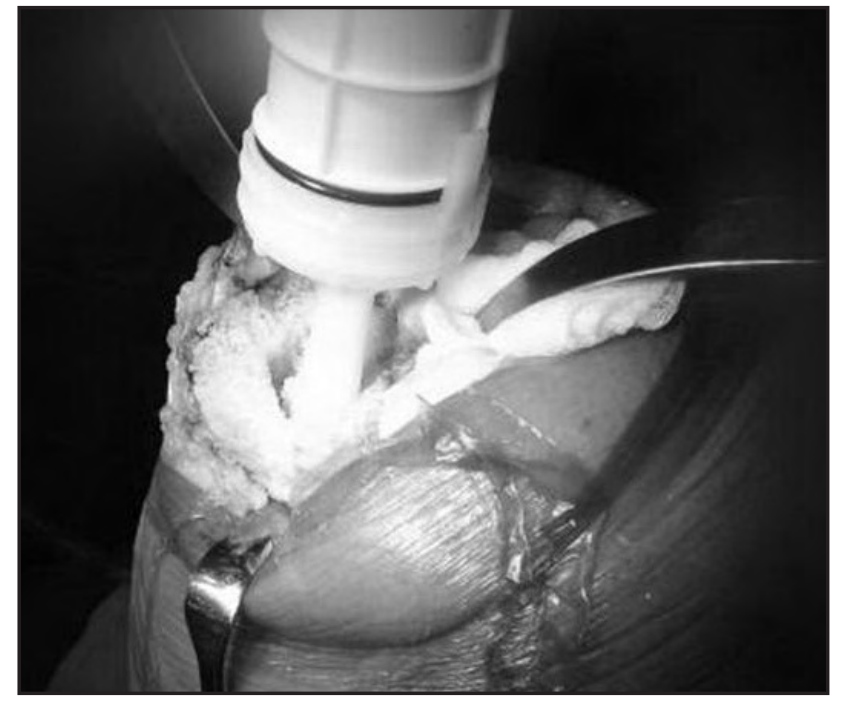

Fig. 1: Cement gun used for cementing the proximal tibia.

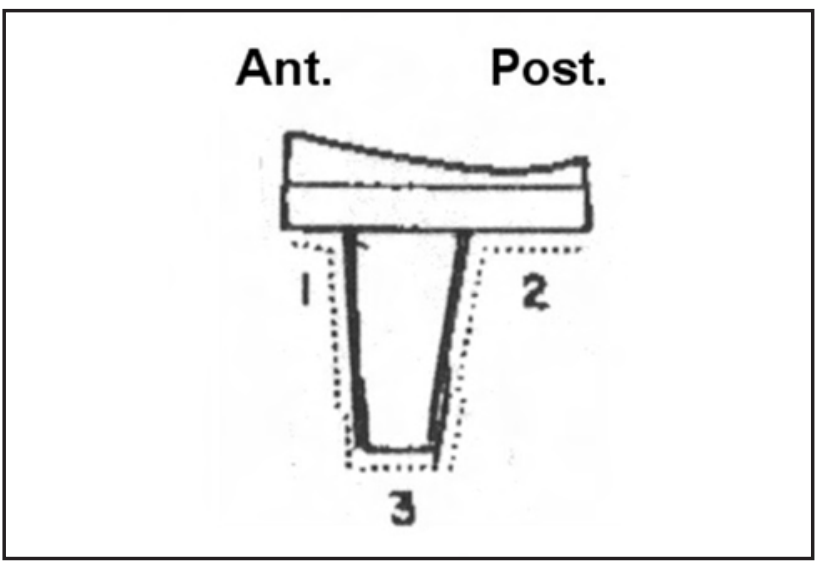

Fig. 3: The zones in the tibia as seen in a lateral view $x$-ray.

Cemented tibial implants have been shown to display significantly less micromotion initially than uncemented tibial implants ${ }^{26}$. This may be due to the fact that the cement acts as a mechanical reinforcement to the structure of the proximal tibia metaphysics. Good cementing is therefore very important. Although studies ${ }^{1,27,28}$ have shown acceptable penetration of cement after standard bone preparation, such procedures generally result in only cement penetration between 2 to $4 \mathrm{~mm}$. The presence of a partial radiolucent line in immediate post operative films is thought to be due to poor cement penetration and not due to lysis ${ }^{28}$. This type of radiolucency is thought to be due to failure of interlocking action between the cement and bone ${ }^{29}$, and may facilitate the entry of wear debris into the bone cement interface and progress to osteolysis and loosening. Of the patients in Group 2, 65.9\% had a good bone cement interface with no radiolucent lines in any zone compared to $34.1 \%$ of patients in group 1. Walker et al. showed that the depth of cement penetration was inversely related to the development of radiolucent lines ${ }^{30}$.

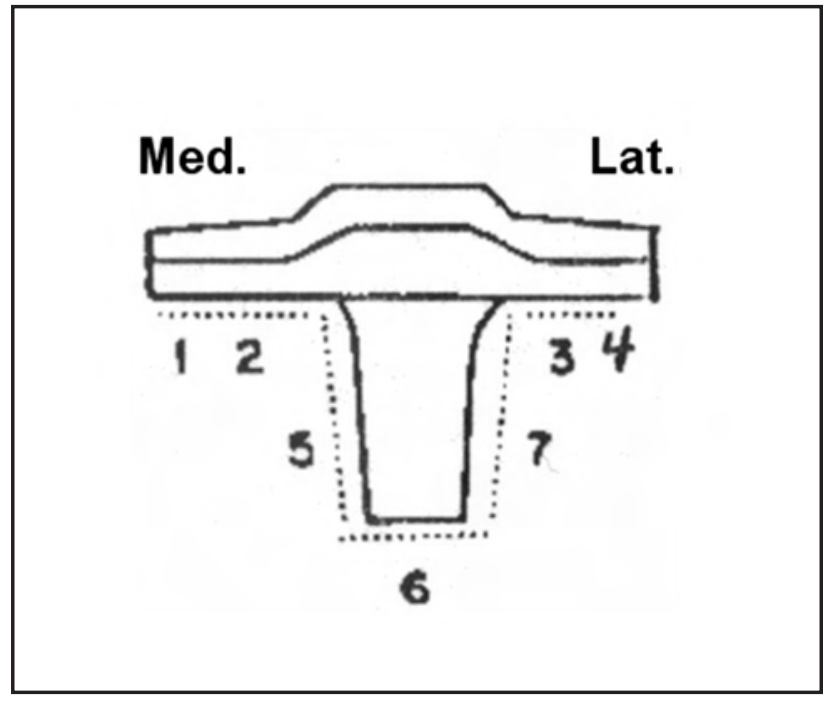

Fig. 2: The zones in the tibia as seen from an (anterior-posterior) AP view $x$-ray.

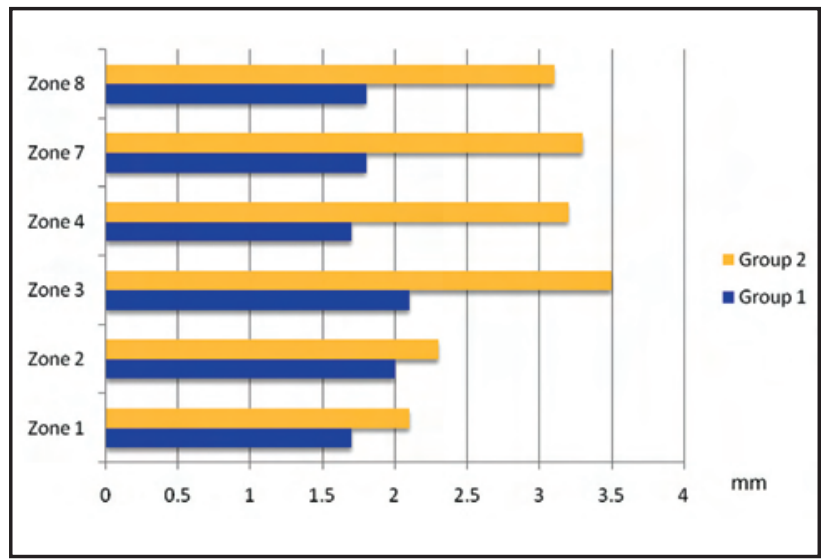

Fig. 4: Comparison of the median values of cement penetration between the 2 different groups at the 6 zones of interest.

Cement penetration between the medial and lateral sides of the implant was not symmetrical; there was statistically significantly better cement penetration on the lateral side (zone 3 ) as compared to medial zones 1 and $2(\mathrm{p}<0.009$ and $\mathrm{p}<0.004)$. This limitation is most probably due to sclerosis of the medial side of the tibia that is commonly seen in severe osteoarthritis, probably reducing the pressure with which cement can be pushed into the cut bone surfaces. However the cement gun increases the depth of cement penetration by 0.3 to $1.5 \mathrm{~mm}$. Although the number is small, it amounts to $15 \%$ to $83 \%$ improvement compared to usual cementing methods employed in group 1.

Contamination of bone surfaces with blood before cement application may reduce the shear strength of the cement bone interface. Many surgeons employ some sort of lavage to remove blood from the bone surfaces ${ }^{10}$ and / or apply hydrogen peroxide to the cut bone surfaces. We observed blood, marrow and fat being extruded from the tibia during active pressurization of the cement by the cement gun, that further removed blood and fat from the bone surfaces and 
enabled cement better fixation. The use of the cement gun is not a novel way to improve the depth of cement penetration. Other researchers have also shown that use of a cement gun improves cementing ability during $\mathrm{TKA}^{31}$.

In this study, there were three different participating surgeons, making it likely that subtle differences in the surgical technique for cement application and/or the force used for tibial base plate implantation made for differences in the depth of cement penetration. Similarly, the brands of cement used in the two hospitals were not the same, and this discrepancy could have impacted the depth of the cement penetration due to differing viscosities.

\section{CONCLUSION}

Use of a cement gun helps to increase the cement penetration into the proximal tibia based on radiological evaluation. The result corresponds with lower rate of radiolucent line in cases where cement gun was used.

\section{ACKNOWLEDGEMENTS}

We would like to thank Dr. Maria Lee Hooi Sean, the head of the Clinical Research Centre of Sumtanah Aminah Hospital for helping in the preparation of this article. 


\section{REFERENCES}

1. Bauze AJ, Costi JJ, Stavrou P, Rankin WA, Hearn TC, Krishnan J, et al. Cement penetration and stiffness of the cement-bone composite in the proximal tibia in a porcine model. J Orthop Surg (Hong Kong) 2004; 12(2): 194-8

2. Jones EC, Insall JN, Inglis AE, Ranawat CS. GUEPAR knee arthroplasty results and late complications. Clin Orthop Relat Res 1979; 140: 145-52.

3. Grewal R, Rimmer MG, Freeman MA. Early migration of prostheses related to long-term survivorship. Comparison of tibial components in knee replacement. J Bone Joint Surg 1992; 74-B(2): 239-42.

4. Windsor RE, Scuderi GR, Moran MC, Insall JN. Mechanisms of failure of the femoral and tibial components in total knee arthroplasty. Clin Orthop Relat Res 1989;248: 15-9; discussion 19-20.

5. Luring C, Perlick L, Trepte C, Linhardt O, Perlick C, Plitz W, et al. Micromotion in cemented rotating platform total knee arthroplasty: cemented tibial stem versus hybrid fixation. Arch Orthop Trauma Surg 2006; 126(1): 45-8.

6. Cristofolini L, Affatato S, Erani P, Leardini W, Tigani D, Viceconti M. Long-term implant-bone fixation of the femoral component in total knee replacement. Proc Inst Mech Eng (H) 2008; 222(3): 319-31.

7. Petersen MM, Lauritzen JB, Pedersen JG, Lund B. Decreased bone density of the distal femur after uncemented knee arthroplasty. A 1-year follow-up of 29 knees. Acta Orthop Scand 1996; 67(4): 339-44.

8. Shanbhag, A.S., Use of bisphosphonates to improve the durability of total joint replacements. J Am Acad Orthop Surg 2006; 14(4): 215-25

9. Lonner JH, Klotz M, Levitz C, Lotke PA. Changes in bone density after cemented total knee arthroplasty: influence of stem design. J Arthroplasty 2001; 16(1): 107-11.

10. Lutz MJ, Halliday BR. Survey of current cementing techniques in total knee replacement. ANZ J Surg 2002;72(6): 437-9.

11. Peters CL, Craig MA, Mohr RA, Bachus KN. Tibial component fixation with cement: full- versus surface-cementation techniques. Clin Orthop Relat Res 2003; 409: 158-68.

12. Toksvig-Larsen S, Ryd L. Surface characteristics following tibial preparation during total knee arthroplasty. J Arthroplasty 1994; 9(1): 63-6.

13. Aglietti P, Buzzi R, De Felice R, Giron F. The Insall-Burstein total knee replacement in osteoarthritis: a 10-year minimum followup. J Arthroplasty 1999; 14(5): 560-5.

14. Kim YH, Walker PS, Deland JT. A cement impactor for uniform cement penetration in the upper tibia. Clin Orthop Relat Res 1984; 182: 206-10.

15. Stannage K, Shakespeare D, Bulsara M. Suction technique to improve cement penetration under the tibial component in total knee arthroplasty. Knee 2003; 10(1): 67-73.

16. Banwart JC, McQueen DA, Friis EA, Graber CD. Negative pressure intrusion cementing technique for total knee arthroplasty. $J$ Arthroplasty 2000; 15(3): 360-7.

17. OhI, Harris WH. A cement fixation system for total hip arthroplasty. Clin Orthop Relat Res 1982; 164: p. 221-9.

18. Russotti, GM, Coventry MB, Stauffer RN. Cemented total hip arthroplasty with contemporary techniques. A five-year minimum follow-up study. Clin Orthop Relat Res 1988; 235: 141-7.

19. Barrack RL, Mulroy RD Jr, Harris WH, Improved cementing techniques and femoral component loosening in young patients with hip arthroplasty. A 12-year radiographic review. J Bone Joint Surg 1992; 74-B(3): 385-9.

20. Bosco JA, Lachiewicz PH, DeMasi R. Survivorship analysis of cemented high modulus total hip arthroplasty. Clin Orthop Relat Res 1993; 294: 131-9.

21. Hashemi-NejadA, Birch NC, Goddard NJ. Current attitudes to cementing techniques in British hip surgery. Ann R Coll Surg Engl 1994; 76(6): 396-400.

22. Katz RP, Callaghan JJ, Sullivan PM, Johnston RC. Results of cemented femoral revision total hip arthroplasty using improved cementing techniques. Clin Orthop Relat Res 1995; (319): 178-83. 
23. Frederick C, Ewald M. The Knee Society Total Knee Arthroplasty Roentgenographic Evaluation and Scoring System. Clin Orthop Relat Res 1989 Nov; 948(9-12).

24. Guha AR, Debnath UK, Graham NM. Radiolucent lines below the tibial component of a total knee replacement (TKR)-a comparison between single-and two-stage cementation techniques. Int Orthop 2008; 32(4): 453-7.

25. Ryd, L. Micromotion in knee arthroplasty. A roentgen stereophotogrammetric analysis of tibial component fixation. Acta Orthop Scand Suppl 1986; 220: 1-80.

26. Nilsson KG, Kärrholm J, Carlsson L, Dalén T. Hydroxyapatite coating versus cemented fixation of the tibial component in total knee arthroplasty: prospective randomized comparison of hydroxyapatite-coated and cemented tibial components with 5-year follow-up using radiostereometry. J Arthroplasty 1999; 14(1): 9-20.

27. Clarius M, Hauck C, Seeger JB, James A, Murray DW, Aldinger PR. Pulsed lavage reduces the incidence of radiolucent lines under the tibial tray of Oxford unicompartmental knee arthroplasty : Pulsed lavage versus syringe lavage. Int Orthop 2009 Feb 14; Epub ahead of print.

28. Labutti RS, Bayers-Thering M, Krackow KA. Enhancing femoral cement fixation in total knee arthroplasty. J Arthroplasty 2003; 18(8): 979-83.

29. Cornell CN, Ranawat CS, Burstein AH. A clinical and radiographic analysis of loosening of total knee arthroplasty components using a bilateral model. J Arthroplasty 1986; 1(3): 157-63.

30. Walker PS, Soudry M, Ewald FC, McVickar H. Control of cement penetration in total knee arthroplasty. Clin Orthop Relat Res 1984; 185: 155-64.

31. Lutz MJ, Pincus PF, Whitehouse SL, Halliday BR. The Effect of Cement Gun and Cement Syringe Use on the Tibial Cement Mantle in Total Knee Arthroplasty. J Arthroplasty 2009; 24(3): 461-7. 